\title{
Search for Pleiotropic QTL on Chromosome BTA6 Affecting Yield Traits of Milk Production
}

\author{
G. Freyer, ${ }^{\star}$ P. Sørensen,†,\#, C. Kühn, ${ }^{\star}$ R. Weikard,* and I. Hoeschele†,§ \\ ${ }^{*}$ Research Institute for the Biology of Farm Animals \\ Dummerstorf, D-18196 \\ Departments of †Dairy Science and §Statistics, \\ Virginia Polytechnic Institute and State University \\ Blacksburg, VA-24061-0315 \\ \#Department of Animal Breeding and Genetics, \\ Danish Institute of Agricultural Sciences Research Centre \\ Tjele, DK-8830
}

\section{ABSTRACT}

The primary aim of this study was to investigate whether previous findings of similar quantitative trait loci (QTL) positions for correlated yield traits are due to a pleiotropic QTL. We applied a multitrait variance component based QTL mapping method to a dataset involving five granddaughter families from the German Holstein dairy cattle population. The marker map contained 16 microsatellite markers, distributed across chromosome BTA6. A chromosomewise significance threshold was used, because BTA6 is known to harbor QTL for several milk traits. To evaluate the results from the multivariate, across-family analysis, we also conducted single-family analyses using the least squares method of QTL estimation. The results provided two significant QTL findings at 49 and $64 \mathrm{cM}$ for milk yield in different families and putative QTL at 68 $\mathrm{cM}$ for fat yield and at $71 \mathrm{cM}$ for protein yield in another family. The results for fat and protein yield were confirmed by a univariate, across-family variance components analysis. The multivariate analysis of three bivariate trait combinations resulted in a significant pleiotropic QTL finding at $68 \mathrm{cM}$ for fat yield and protein yield, bracketed by markers TGLA37 and FBN13. The estimates of variance contribution due to this QTL were $23 \%$ and $25 \%$, respectively.

(Key words: milk yield traits, QTL mapping, multivariate analysis)

Abbreviation key: AIREML = average information restricted maximum likelihood, $\mathbf{C V C}=$ covariance components, DYD = daughter yield deviations, IBD = identity by descent, $\mathbf{L R}=$ likelihood ratio, $\mathbf{L S}=$ least squares.

Received August 1, 2002.

Accepted October 1, 2002.

Corresponding author: Gertraude Freyer; e-mail: freyer@ fbn-dummerstorf.de.

\section{INTRODUCTION}

A number of studies for detecting quantitative trait loci (QTL) in dairy cattle breeding have been conducted with an emphasis on production traits (e.g., Georges et al., 1995; Lien et al., 1995; Zhang et al., 1998; Ashwell and van Tassel, 1999; Kühn et al., 1999; Velmala et al., 1999; van Tassel et al., 2000; Ron et al., 2001; Freyer et al., 2002). These studies were based mostly on the granddaughter design rather than on the daughter design and have produced several QTL findings on chromosome BTA6. Mosig et al. (2001) presented an overview of the recently published QTL suggestions for milk traits along with their own results from a whole genome scan. The approaches for QTL estimation differ with respect to inclusion of polygenic effects besides the QTL, the number of QTL, treating QTL effects as fixed or random, utilization of multiple linked markers, and experimental design. In addition, the studies also differ as to whether a least squares, a maximum likelihood, a restricted maximum likelihood, or a Bayesian method is used (Hoeschele et al., 1997).

To the best of our knowledge, results of QTL findings in dairy cattle have been reported on the basis of univariate analyses until now. Such results provide only partial information on the genetic architecture of milk production, and univariate analyses do not optimally use the available information.

The multivariate QTL mapping methods take advantage of the correlation structure of the traits. In this way, they achieve higher statistical power for detecting QTL and higher precision of parameter estimates compared to univariate QTL mapping methods (Jiang and Zeng, 1995; Sørensen, 2000). Using multitrait QTL mapping method enables researchers to detect pleiotropic QTL and to distinguish them from closely linked trait-specific QTL.

In this study, we used a multivariate QTL mapping based on the variance component model (e.g., Grignola et al., 1996; Sørensen, 2000). An "average information 
Table 1. Microsatellite markers on chromosome BTA6 used in this study (based on Kühn et al., 1999, extended) with their locations (cM, Kosambi map) and heterozygous sires.

\begin{tabular}{llcll}
\hline $\begin{array}{l}\text { Marker number } \\
\text { and name }\end{array}$ & $\begin{array}{l}\text { Map position } \\
(\mathrm{cM})\end{array}$ & $\begin{array}{l}\text { Marker } \\
\text { heterozygosity }\end{array}$ & $\begin{array}{l}\text { Heterozygous } \\
\text { sires }\end{array}$ & \\
\hline 1 & ILST093 & 0 & 0.47 & $1,2,3$ \\
2 & ILST090 & 16 & 0.55 & $1,2,3,4$ \\
3 & URB16 & 40 & 0.70 & $1,3,5$ \\
4 & BM1329 & 43 & 0.46 & 4,5 \\
5 & FBN12 & 58 & 0.81 & $1,3,4,5$ \\
6 & BM143 & 59 & 0.84 & 3,5 \\
7 & DIK82 & 64 & 0.78 & 1,3 \\
8 & TGLA37 & 66 & 0.64 & 1,4 \\
9 & FBN9 & 67 & 0.83 & 1,2 \\
10 & FBN13 & 71 & 0.49 & $1,4,5$ \\
11 & FBN10 & 76 & 0.58 & $1,2,3,4,5$ \\
12 & ILSTS097 & 79 & 0.53 & $1,2,3$ \\
13 & FBN14 & 89 & 0.57 & $1,2,3$ \\
14 & CSN & 95 & 0.44 & 1,4 \\
15 & BP7 & 102 & 0.76 & 2,4 \\
16 & BMC4203 & 124 & 0.94 & \\
\hline
\end{tabular}

restricted maximum likelihood" (AIREML) method, developed by Jensen and Madsen (1994), was adapted for estimating the positions and variance contributions of QTL affecting one or several traits in addition to additive polygenic and residual variance components. This method is based on a random QTL model, where phenotypes, QTL effects, and polygenic effects are assumed to be normally distributed.

We also performed univariate single-family analyses based on the least squares (LS) method to investigate whether main deviations in the putative QTL positions between individual families exist and how these affect the result of the multitrait analysis.

The objective of our study was to obtain multivariate QTL mapping results for yield traits and to compare these results to previous findings from different univariate analyses. A significant QTL for fat yield and for protein yield was found, with very similar QTL positions for both traits (Kühn et al., 1999; Freyer et al., 2002). Thus, the main goal of the present paper was to determine whether there is a pleiotropic QTL on chromosome 6 affecting milk yield traits.

\section{MATERIALS AND METHODS}

\section{Animals}

The sons of five German Holstein Friesian sires in half sib families $\mathrm{S} 1$ to $\mathrm{S} 5$ were genotyped for 16 microsatellite markers on chromosome BTA6 (Table 1). The pool of sons with complete phenotypic data for the milk yield traits (Table 2 ) was reduced to the genotyped animals. We used both the daughter yield deviations (DYD) and the estimated breeding values (EBV) in the QTL analysis. The correlation coefficients for DYD and EBV were 0.89 for milk yield, 0.91 for fat yield and 0.87 for protein yield. DYD is the actual deviation of sires' daughter performances from contemporaries (VanRaden and Wiggans, 1991). The phenotypes of the daughters were adjusted for the fixed environmental effects, including effects of herd, year, and season of calving) and for genetic values of their dams. EBV is based on DYD and includes weighted information from all available relatives and is a regressed measure. The German method of estimating breeding values was described in the annual reports of the Computing Centre for Animal Breeding, VIT Verden (e.g., VIT, 2001). To ensure complete phenotypic information on the DYD data for the genotyped sons, we used the 1996 evaluation data. QTL analysis based on granddaughter design requires weighting of the trait values (e.g., Grignola et al., 1996; Zhang et al., 1998). The reliabilities of EBV were computed as squared correlations of sire's predicted and true transmitting abilities, described by VanRaden and Wiggans (1991). The reliabilities can account for information on all relatives and had to be considered for weighting of EBV of son $j$ of sire $i$ in terms of $z_{i j}=1 / R E L_{i j}$, and accordingly $z_{i j}=1 / n_{\text {dij }}$ for DYD, where $n_{d}$ is the number of daughters. Sons without complete genetic evaluations on traits or without genotypes for the markers, which were informative in the particular family, were excluded.

\section{Statistical Methods}

The novel contribution of our analysis consists of QTL mapping with an across-family analysis for bivariate yield trait combinations. This QTL mapping method (Sørensen, 2000) is based on AIREML (Jensen et al., 1997) and uses the DMU-package, developed at the Danish Institute for Agricultural Sciences (Jensen and 
Table 2. Overall means in kilograms and standard deviations (SD) of trait values for available sons across five half-sib families for milk yield, fat yield, and protein yield and statistics of genotyping within the families.

\begin{tabular}{|c|c|c|c|c|c|c|c|c|c|c|}
\hline \multirow{2}{*}{$\begin{array}{l}\text { Family code } \\
\text { Number of available sons } \\
\text { Milk trait }\end{array}$} & \multicolumn{2}{|l|}{$\begin{array}{c}\text { S1 } \\
203\end{array}$} & \multicolumn{2}{|l|}{$\begin{array}{c}\text { S2 } \\
126\end{array}$} & \multicolumn{2}{|l|}{$\begin{array}{l}\text { S3 } \\
69\end{array}$} & \multicolumn{2}{|l|}{$\begin{array}{l}\text { S4 } \\
17\end{array}$} & \multicolumn{2}{|l|}{$\begin{array}{c}\text { S5 } \\
147\end{array}$} \\
\hline & mean & SD & mean & SD & mean & SD & mean & $\mathrm{SD}$ & mean & SD \\
\hline Protein yield & 12.2 & 11.7 & 15.6 & 14.0 & 13.0 & 11.7 & 12.6 & 11.0 & 24.1 & 11.3 \\
\hline Information on sons: & & & & & & & & & & \\
\hline Number of daughters & 771 & 317 & 143 & 54 & 180 & 125 & 162 & 43 & 134 & 46 \\
\hline Genotyped sons & 72 & & 65 & & 27 & & 17 & & 117 & \\
\hline
\end{tabular}

Madsen, 1994). To evaluate the results from the multivariate analysis, we also conducted a weighted LS analysis for single families and single traits.

LS Method. Multimarker regression (e.g., Knott et al., 1994) was implemented in a computer program by Du and Hoeschele (1999). The probability of inheriting a particular sire QTL allele was calculated for each son in $1 \mathrm{cM}$ steps along the chromosome, using the information on the closest informative flanking markers. The trait values were regressed on this conditional probability.

The model including $\mathrm{n}$ QTL, based on the granddaughter design, was

$$
\mathrm{y}_{\mathrm{ij}}=\mu+\mathrm{s}_{\mathrm{i}}+\sum_{\mathrm{q}=\mathrm{l}}^{n} \mathrm{~b}_{\mathrm{ik}} \mathrm{P}_{\mathrm{ijkl}}+\mathrm{e}_{\mathrm{ij}},
$$

where $y_{i j}$ was the trait value of son $j$ of (grand)sire $i$, (i $=1, \ldots, 5), \mu$ was the overall mean, $\mathrm{s}_{\mathrm{i}}$ represented the fixed effect of (grand)sire $i, b_{i k}$ was a regression coefficient for QTL q nested within (grand)sire i at position $\mathrm{k}$ of QTL $\mathrm{q}$, and $\mathrm{e}_{\mathrm{ij}}$ was the residual with variance approximately equal to $\mathrm{z}_{\mathrm{ij}} \sigma_{\mathrm{e}}^{2}$. The specific use of weights $\mathrm{Z}_{\mathrm{ij}}$ for DYD and EBV is described in the previous section. The number $\mathrm{n}$ of QTL fitted at a time was 1 for the single-family analyses discussed in this paper. $\mathrm{P}_{\mathrm{ijkl}}$ was the probability of son $\mathrm{j}$ inheriting QTL allele $\mathrm{l}$ of from (grand)sire i at position k of QTL q. The probabilities $\mathrm{P}_{\mathrm{ijkl}}$ in equation [1] were calculated as described by Hoeschele (2001), with the most likely linkage phase for sire i treated as the true phase. An F-statistic for $\mathrm{H}_{0}$ (no QTL) vs. $\mathrm{H}_{\mathrm{A}}$ (one QTL present) was calculated at $1 \mathrm{cM}$ intervals. The computer program (Du and Hoeschele, 1999) performing the LS analysis provided 95\% confidence intervals for QTL location by bootstrapping and a chromosomewide significance threshold by data permutation (Churchill and Doerge, 1994). We set the number of permutations to 100,000 and the number of bootstrap samples to 1000 .
(Co)Variance Components (CVC) Method. The data was analyzed by fitting the following multivariate "purely additive" mixed model with n QTL:

$$
\mathbf{y}=\mathbf{X} \boldsymbol{\beta}+\mathbf{Z u}+\sum_{\mathrm{q}=1}^{n} \mathbf{W}_{\mathrm{q}} \mathbf{a}_{\mathrm{q}}+\mathbf{e}
$$

where $\mathbf{y}$ was a vector of $t=2$ yield traits observed for each son of each grandsire. Matrices $\mathbf{X}$ and $\mathbf{Z}$ were known design matrices, associating the observations of each son to the fixed and random effects, $\beta$ was a vector of fixed effects (here containing the overall trait means), $\mathbf{u}$ was the vector of random polygenic effects of the (grand)sires and their sons, and e represents the vector of random residual effects. $\mathbf{W}_{\mathbf{q}}$ was a matrix relating each individuals record to its unknown additive QTL effect. The genotypic part was modeled by $\mathbf{a}_{\mathrm{q}}$, the vector of random genotypic effects for QTL q. The QTL effects, the polygenic effects, and the residuals were assumed to be normally distributed with expectation and covariance matrices $\left(\mathbf{0}, \mathbf{K}_{0}^{t} \otimes \mathbf{Q}_{\mathbf{k} \mid \mathbf{M}}\right),\left(\mathbf{0}, \mathbf{G}_{0}^{t} \otimes \mathbf{A}\right)$ and $(\mathbf{0}$, $\left.\mathrm{z}_{\mathrm{ij}} \mathbf{E}_{0}^{t} \otimes \mathbf{I}\right)$, respectively.

The dimension of the unknown $\mathrm{t} \times \mathrm{t}$ covariance matrix $\mathbf{K}_{0}{ }_{0}$ depended on the number of traits $\mathrm{t}$ (here $\mathrm{t}=1$ or $\mathrm{t}$ $=2$ ) affected by the QTL. Matrices $\mathbf{G}_{0}^{t}$ and $\mathbf{E}_{0}^{t}$ were unknown $\mathrm{t} \times \mathrm{t}$ covariance matrices of additive genetic and residual effects, respectively. Also, A was the numerator relationship matrix, I was an identity matrix, and $\otimes$ denotes the direct product of matrices. Matrix $\mathbf{Q}_{\mathbf{k} \mid \mathbf{M}}$ was the genotypic identity by descent (IBD) matrix at QTL position $\mathrm{k}$. The IBD matrix is a function of marker data (M) and position (k) of the QTL q on the chromosome. The weighting $\mathrm{z}_{\mathrm{ij}}$ was introduced in the Animals section.

Calculating IBD probabilities. The genotypic IBD matrix for a QTL, $\mathbf{Q}_{\mathbf{k} \mid \mathbf{M}}$, was computed by first constructing the allelic or gametic relationship matrix with the method of Fernando and Grossman (1989), extended to flanking markers (Grignola et al., 1996), and 
Table 3. Probability of inheriting QTL allele 1 or 2 from sire s for offspring o, given the nearest informative flanking marker haplotype inherited from sire s and a specific QTL position k.

\begin{tabular}{|c|c|c|c|}
\hline \multicolumn{2}{|c|}{$\begin{array}{c}\text { Inheritance of } \\
\text { marker haplotype } \mathbf{H}=\left(\mathrm{M}_{\mathrm{i}} \mathrm{M}_{\mathrm{j}}\right)\end{array}$} & \multirow[b]{2}{*}{$P\left(g_{0}^{\text {pat }} \equiv g_{s}^{1} \mid \mathbf{H}\right)^{1}$} & \multirow[b]{2}{*}{$P\left(g_{0}^{p a t} \equiv g_{s}^{2} \mid \mathbf{H}\right)$} \\
\hline $\mathrm{M}_{\mathrm{i}}$ & $\mathrm{M}_{\mathrm{j}}$ & & \\
\hline $1^{2}$ & 1 & $\left(1-r_{i Q}\right)\left(1-r_{Q j}\right) /\left(1-r_{i j}\right)^{3}$ & $\mathrm{r}_{\mathrm{iQ}} \mathrm{r}_{\mathrm{Qj}} /\left(1-\mathrm{r}_{\mathrm{ij}}\right)$ \\
\hline 1 & 2 & $\left(1-r_{i Q}\right) r_{Q j} /\left(1-r_{i j}\right)$ & $r_{\mathrm{iQ}}\left(1-r_{\mathrm{Qj}}\right) /\left(1-r_{\mathrm{ij}}\right)$ \\
\hline 2 & 1 & $r_{i Q}\left(1-r_{Q j}\right) /\left(1-r_{i j}\right)$ & $\left(1-r_{i Q}\right) r_{Q j} /\left(1-r_{i j}\right)$ \\
\hline 2 & 2 & $r_{i Q} r_{Q j} /\left(1-r_{i j}\right)$ & $\left(1-r_{i Q}\right)\left(1-r_{Q j}\right) /\left(1-r_{i j}\right.$ \\
\hline 1 & Unknown & $\left(1-r_{\mathrm{iQ}}\right)$ & $\mathrm{r}_{\mathrm{iQ}}$ \\
\hline 2 & Unknown & $\mathrm{r}_{\mathrm{iQ}}$ & $\left(1-r_{i Q}\right)$ \\
\hline Unknown & 1 & $\left(1-r_{Q j}\right)$ & $\mathrm{r}_{\mathrm{Qj}}$ \\
\hline Unknown & 2 & $\mathrm{r}_{\mathrm{Qj}}$ & $\left(1-r_{Q j}\right)$ \\
\hline Unknown & Unknown & 0.5 & 0.5 \\
\hline
\end{tabular}

with the most likely linkage phase of the sires treated as known. Subsequently, the genotypic IBD matrix was formed from the gametic IBD matrix as described by George et al. (2000). We computed the IBD probabilities for the QTL alleles in the sons conditional on the closest informative marker bracket inherited from a sire (Table $3)$. The genotypic IBD matrix $\mathbf{Q}_{\mathbf{k} \mid \mathbf{M}}$ was computed, conditional on QTL position $\mathrm{k}$, in $1 \mathrm{cM}$ steps along the chromosome.

Multivariate analysis. The restricted likelihood (Patterson and Thompson, 1971) of the multivariate mixed model was maximized with respect to the covariance matrices $\left(\mathbf{K}_{0}^{t}, \mathbf{G}_{0}^{t}\right.$, and $\left.\mathbf{E}_{0}^{t}\right)$ conditional on the IBD matrix. The maximization of the restricted likelihood was achieved using an efficient algorithm, known as AIREML (described by Jensen et al., 1997). Recently, Hansen et al. (2002) demonstrated this algorithm in more detail, provided additional information on the DMU-package in this journal and reported genetic parameter estimates for several traits in dairy cattle. Our univariate and bivariate AIREML analyses were based on a sequence of models, always including the fixed effects, polygenic effects and residuals but differing in the QTL effects on the traits (Table 4). Specifically, the analyses were performed with the following models:

(MPLEI) a pleiotropic model containing a single QTL q, affecting traits 1 and 2 with (co)variance matrix $\mathrm{K}_{0}\left(\begin{array}{cc}\sigma_{q 1}^{2} & \sigma_{q 12} \\ \sigma_{q 21} & \sigma_{q 2}^{2}\end{array}\right)$ and position $\mathrm{k}_{12}$;

(MQ1) a model containing a single QTL q, affecting trait 1 only, with QTL variance $\mathrm{K}_{0}=\left(\sigma_{q 1}^{2}\right)$ and position $\mathrm{k}_{1}$;

(MQ2) a model containing a single QTL q, affecting trait 2 only, with QTL variance $\mathrm{K}_{0}=\left(\sigma_{q 2}^{2}\right)$ and position $\mathrm{k}_{2}$;

(MPOLY) the fully reduced model without any QTL effects and

(MQ1Q2) a linkage model with two linked QTL affecting only trait $1\left(\mathrm{q}_{1 \_1}\right)$ and only trait $2\left(\mathrm{q}_{2 \_}\right)$, respectively, with $\mathbf{K}_{0}^{1}=\left(\sigma_{q 1}^{2}\right)$, and $\mathbf{K}_{0}^{2}=\left(\sigma_{q 2}^{2}\right)$, and with positions $\mathrm{k}_{1 \_1}$ unequal to $\mathrm{k}_{2 \_}$, respectively.

Accordingly, we also conducted a univariate CVC analysis, based on

(UQ1) a model containing one single QTL q, with QTL variance $\mathrm{K}_{0}=\left(\sigma_{q}^{2}\right)$ and position $\mathrm{k}$ and (UPOLY) the simple polygenic model.

Hypothesis tests were based on the asymptotic distribution of the likelihood ratio (LR) test statistic

$$
L R=-2\left(L_{\text {reduced }}-L_{\text {full }}\right) \sim \chi d f^{2}
$$

where $L_{\text {reduced }}$ and $L_{\text {full }}$ are the logarithms of the maximized likelihoods under the reduced model and full model, respectively. The reduced model was either the no-QTL model (MPOLY) in testing the null hypothesis of no QTL for both traits, or either bivariate model with a QTL affecting only one trait (MQ1) or (MQ2), against (MPLEI) in the case of testing for a pleiotropic QTL effect (Table 4). The number of degrees of freedom (df) was the difference in the number of free parameters between two models. We assumed that the existence of multiple QTL on chromosome 6 affecting several milk traits is known from the literature, including our own previous results (e.g., van Tassel et al., 2000; Ron et al., 2001; Mosig et al., 2001; Freyer et al., 2002, to mention only very recent publications). For this reason 
Table 4. Multivariate mixed models (MPLEI to MQ1Q2) and univariate models (UPOLY and UQ1), including QTL parameters (x), putative QTL positions $(\mathrm{k})$, and tests of two hypotheses for the multivariate mixed model results: no QTL vs. QTL specified by the model and no pleiotropic QTL vs. QTL for two single traits, (including degrees of freedom (df).

\begin{tabular}{|c|c|c|c|c|c|c|c|}
\hline \multirow[b]{2}{*}{ Model } & \multirow{2}{*}{$\begin{array}{l}\text { Parameters } \\
\text { (total } \\
\text { number) }\end{array}$} & \multicolumn{5}{|c|}{ QTL parameters $^{1}$} & \multirow{2}{*}{$\begin{array}{l}\text { Null hypothesis model in LR } \\
\text { Test for model (df) }\end{array}$} \\
\hline & & $\mathrm{k} 1$ & $\mathrm{k} 2$ & Cov & Var1 & Var2 & \\
\hline MPLEI & 9 & \multicolumn{2}{|c|}{$\mathrm{x}$} & $\mathrm{x}$ & $\mathrm{x}$ & $\mathrm{x}$ & \\
\hline MQ1 & 7 & $\mathrm{x}$ & - & - & $\mathrm{x}$ & - & MPLEI (2) \\
\hline MQ2 & 7 & - & $\mathrm{x}$ & - & - & $\mathrm{x}$ & MPLEI (2) \\
\hline MPOLY & 6 & - & - & - & - & - & MPLEI (3), MQ1 and MQ2 (1) \\
\hline MQ1Q2 & 9 & $\mathrm{x}$ & $\mathrm{x}$ & - & $\mathrm{x}$ & $\mathrm{x}$ & - \\
\hline UQ1 & 3 & $\mathrm{x}$ & - & - & $\mathrm{x}$ & - & \\
\hline UPOLY & 2 & - & - & - & - & - & UQ1 (1) \\
\hline
\end{tabular}

${ }^{1} \operatorname{Var} 1$ (Var2) is the additive QTL variance for trait 1 (2). Cov is the covariance between QTL effects on traits 1 and 2. $\mathrm{k} 1$ (k2) are the most likely QTL positions for trait 1 (trait 2) obtained by covariance component (CVC) analysis.

we used a chromosomewise significance threshold based on the nominal type I error probability of $\alpha=$ 0.05 instead of a genomewise threshold.

\section{RESULTS AND DISCUSSION}

We present QTL mapping results with respect to milk yield, fat yield, and protein yield, because they are the biologically interesting milk production traits and because they are positively correlated. Here, applying a multivariate QTL mapping analysis could help to better understand the structure of the genetic correlations. Single-family analyses using LS and univariate AIREML analyses across the families were performed in addition to the multivariate analyses. We analyzed both "response variables" DYD and EBV for each yield trait in order to investigate the effect of the response variables on the QTL mapping results. In most cases, the non-QTL variance, as a sum of polygenic and residual variance, in relation to the QTL variance was lower for EBV than for DVD. The putative QTL locations were equal for DYD and EBV when reaching the significance level. Thus, we restrict to reporting results from EBV only. In general, using DYD for QTL estimation has been recommended, because of the preference of a phenotypic over a regressed measure. Several studies supported this recommendation, while others showed that analysis of EBV lead to accurate estimates of QTL positions (e.g., Israel and Weller, 2002, cited the method by Whittaker et al., 1996).

\section{Single-Family Analysis}

Single-family analyses based on the LS method (Table 5) revealed putative QTL positions for single traits, exceeding the significance threshold for fat yield at 68 $\mathrm{cM}$ and at $71 \mathrm{cM}$ for protein yield in family S2. Significant QTL positions for milk yield were obtained from two different families, suggesting QTL locations at 49 (family S1) and at $64 \mathrm{cM}$ (family S5), respectively. The latter position is located between markers BM143, which both Gomez-Raya et al. (1998) and Velmala et al. (1999) found to be associated with milk yield, and TGLA37. Ron et al. (2001) reported QTL for yield traits in the region between 51 and $58 \mathrm{cM}$ in a single family. In our study, additional putative QTL for fat yield with positions at 61 and $91 \mathrm{cM}$ were near the significance threshold in families S1 and S3. An illustration of the wide confidence intervals (Table 5) can be found in Figure 1 for milk yield. Family S1 showed two peaks in the test statistic profile. Thus, the confidence interval, 27 to $97 \mathrm{cM}$, includes both positions. Very similar results exist for family S5. Freyer et al. (2002) reported superiority of the single trait two-QTL model in several families. Here, however, our focus is on a putative pleiotropic QTL, where family S2 is of special interest, as it provides evidence for a single segregating QTL both for fat and protein yield.

\section{Univariate Variance Component Analysis}

The univariate analysis results confirmed a QTL position for fat yield at $67 \mathrm{cM}$ to be significant. The variance contribution of the QTL was 20\%. The two-QTL model was not significantly superior, suggesting QTL positions 67 and $90 \mathrm{cM}$ for fat yield. The position at 67 cM represented the QTL found in family S2 and the 90 cM position resulted from the QTL segregating in family S1 (see Table 5 for comparison). The variance component estimates from the two-QTL model and the oneQTL model were similar for the QTL at $67 \mathrm{cM}$. In addition, a variance component of about $20 \%$ was estimated for the second QTL. The results of the two-QTL model are not shown in detail, because they were meaningless for the other yield traits. The putative QTL position for 
Table 5. Results of the within family analyses of traits milk yield, fat yield, and protein yield based on least squares (LS) method and a one-QTL model.

\begin{tabular}{llcccc}
\hline Family & Trait & $\mathrm{b}^{1}$ & $\operatorname{Pos}^{2}$ & $\mathrm{~F}^{3}$ & $\mathrm{CI}(95)^{4}$ \\
\hline S1 & Milk yield & -437.5 & 49 & $12.10^{\mathrm{a}}$ & $27-97$ \\
& Fat yield & 16.81 & 91 & 8.75 & $40-103$ \\
S2 & Protein yield & 9.55 & 90 & 8.06 & $20-93$ \\
& Milk yield & 249.0 & 71 & 4.19 & $0-121$ \\
& Fat yield & 13.45 & 68 & $8.76^{\mathrm{a}}$ & $0-86$ \\
S3 & Protein yield & 11.94 & 71 & $11.48^{\mathrm{a}}$ & $0-76$ \\
& Milk yield & 702.6 & 110 & 5.24 & $7-117$ \\
& Fat yield & 20.21 & 61 & 7.03 & $41-102$ \\
S4 & Protein yield & 18.82 & 111 & 6.43 & $6-123$ \\
& Milk yield & 472.16 & 77 & 1.84 & $1-102$ \\
& Fat yield & -12.31 & 76 & 1.63 & $1-102$ \\
S5 & Protein yield & 7.29 & 123 & 0.92 & $5-124$ \\
& Milk yield & -327.0 & 64 & $8.29^{\mathrm{a}}$ & $59-102$ \\
& Fat yield & -9.22 & 64 & 4.20 & $40-102$ \\
& Protein yield & -7.7 & 79 & 6.31 & $59-102$ \\
\hline
\end{tabular}

${ }^{\mathrm{a}}$ Indicates exceeding of chromosome wise threshold $(P<0.05)$.

${ }^{1}$ Average regression coefficient of QTL estimate on trait values.

${ }^{2} \mathrm{Pos}=$ position where the highest test statistic value was reached.

${ }^{3}$ Highest $\mathrm{F}$-value in the test statistic profile along the chromosome.

${ }^{4}$ Bootstrap 95\% confidence interval.

protein yield was in the same region as that for fat yield (Table 6). The significant result from the single-family analysis, suggesting a QTL at $71 \mathrm{cM}$ in family S2, was confirmed (here $70 \mathrm{cM}$ ). This result agreed with reports of QTL findings for yield traits by Velmala et al. (1999) and Gomez-Raya et al. (1998). Significant QTL results for milk yield, as found by the within family LS analysis, could not be confirmed. The peak in the test statistic profile suggesting a QTL at $88 \mathrm{cM}$, with an estimated QTL variance contributing about $16 \%$ to the total variance, was fairly distant from the two significant singlefamily results (Figure 1). We noticed high errors of the variance estimates in this case. Other studies (e.g., Lien et al., 1995; Velmala et al., 1998) reported QTL in this

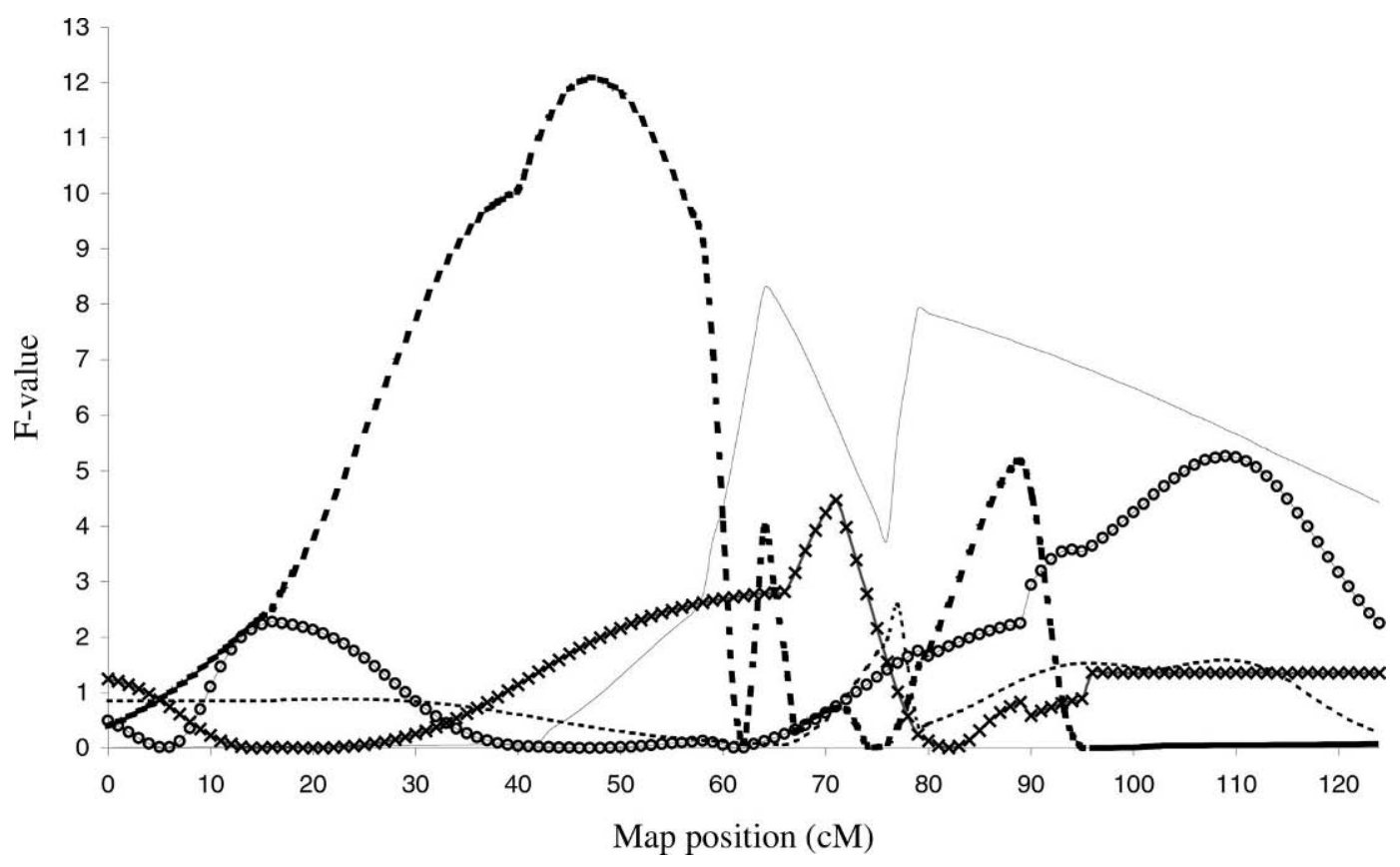

Figure 1. Test statistic profile of single-family analyses for trait milk yield in families $\mathrm{S} 1$ (- - $)$, S2 ( x x ), S3 (-o-), S4 (--), and S5 (-) with the chromosomewise significance level of 9.22 and 7.17 exceeded in family S1 and family S5, respectively. 
Table 6. Test statistic values (LR) and variance components ( \pm standard errors of variance components) from the one-QTL model using univariate covariance component (CVC) across family analysis of traits milk yield, fat yield, and protein yield.

\begin{tabular}{llccc}
\hline Trait & $\begin{array}{l}\text { QTL } \\
\text { position }\end{array}$ & LR & $\begin{array}{l}\text { QTL } \\
\text { variance }\end{array}$ & $\begin{array}{l}\text { non-QTL } \\
\text { variance }\end{array}$ \\
\hline Milk yield & 88 & 4.15 & $35,237 \pm 25,577$ & $182,501 \pm 83,171$ \\
Fat yield & 67 & $8.26^{\mathrm{a}}$ & $72.7 \pm 36.7$ & $287.4 \pm 35.9$ \\
Protein yield & 70 & $11.31^{\mathrm{a}}$ & $41.5 \pm 19.5$ & $108.4 \pm 13.4$ \\
\hline
\end{tabular}

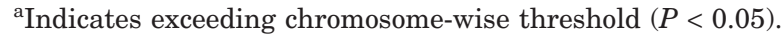

area, within or around the casein locus, which is located at $95 \mathrm{cM}$ on our map.

\section{Multivariate Variance Component Analyses}

A significant pleiotropic QTL result at $68 \mathrm{cM}$ was obtained for the combination fat yield and protein yield (Table 7). This QTL contributed about $23 \%$ and $25 \%$ to the total variance of fat yield and protein yield (Table 8), respectively. Both likelihood ratio (LR) tests (MPLEI:MQ1) and LR (MPLEI:MQ2) were significant, suggesting that this region harbors a pleiotropic QTL affecting both traits simultaneously.

The putative QTL position at $68 \mathrm{cM}$ obtained from the pleiotropic model was in agreement with the QTL positions of 67 and $70 \mathrm{cM}$, obtained from the univariate analyses of fat yield and protein yield, respectively. The range of these related QTL positions, estimated with different methods, both DYD and EBV data, and genetic models, corresponded to an interval of maximum $5 \mathrm{cM}$.

For milk and protein yield, the high LR (MPOLY:MPLEI) suggested a QTL at position $58 \mathrm{cM}$. But this was not in agreement with the single-trait analyses (Table 7). Ron et al. (2001) found a QTL for milk yield at exactly this position. The absence of a more conclusive result might be related to the partially significant family specific QTL positions for milk yield (Table 5). The position of a pleiotropic QTL for milk yield and protein yield was apparently biased by this fact. No evidence was found for a pleiotropic QTL affecting milk yield and fat yield simultaneously.

\section{DISCUSSION}

Because we assumed the existence of several QTL for milk traits on BTA6, our focus was on the identification and confirmation of pleiotropic QTL for the trait combinations of interest. We did confirm a pleiotropic QTL for fat and protein yield, which was fully in agreement with the univariate analysis results and the significant QTL findings for both traits in one family. The Pearson correlation coefficient for these two traits was $0.651(P<0.0001)$. We could not confirm a pleiotropic QTL for milk yield and protein yield, although the correlation was considerably higher $(r=0.811)$. The putative (significant) QTL positions for milk yield were different between the families and also different from the putative QTL position for protein yield. The estimated QTL variance components did not exceed $25 \%$ of the total variance for fat and protein yield. Thus, we may conclude that our pleiotropic QTL finding for fat yield and protein yield was not based exclusively on the part-whole relationship between both traits.

The pleiotropic model (MPLEI) was compared to the close linkage model (MQ1Q2) for trait combination fat and protein yield in terms of the residual variances and

Table 7. Likelihood ratio (LR) test results from the pleiotropic model MPLEI vs. the single bivariate QTL models MQ1 and MQ2 for pairwise trait combinations involving milk yield, fat yield and protein yield in comparison to the LR from the polygenic model MPOLY vs. MPLEI. ${ }^{1}$

\begin{tabular}{llllc}
\hline & $\begin{array}{l}\text { QTL } \\
\text { Traits in combination }\end{array}$ & $\begin{array}{l}\text { LR } \\
\text { (MPLEI: }\end{array}$ & $\begin{array}{l}\text { LR } \\
\text { (MPLEI: } \\
\text { MQ2) }\end{array}$ & $\begin{array}{l}\text { LR } \\
\text { (MPOLY: } \\
\text { MPLEI) }\end{array}$ \\
\hline Milk yield and fat yield & 64 & MQ1) & $<0$ & 2.64 \\
Milk yield and protein yield & 58 & 6.11 & 4.56 & $18.01^{\mathrm{a}}$ \\
Fat yield and protein yield & 68 & $9.76^{\mathrm{c}}$ & $9.80^{\mathrm{c}}$ & $11.01^{\mathrm{b}}$ \\
\hline
\end{tabular}

${ }^{1}$ LR (MPOLY:MPLEI) is the LR from the multitrait model without any QTL and the pleiotropic model (null hypothesis of no QTL at position $\mathrm{k} 1=\mathrm{k} 2$ ), LR (MQ1:MPLEI) or LR (MQ2:MPLEI) is the LR from the simple bivariate model focusing on trait 1 (or trait 2) each and the pleiotropic model (null hypothesis of no pleiotropic QTL at position $\mathrm{k} 1=\mathrm{k} 2$ for trait 1 and trait 2). Suffixes indicate significant results according to the requirements of specific model comparisons (exceeding chromosomewise threshold, $P<0.05$ ): ${ }^{\text {a }} P=$ $0.0004,{ }^{\mathrm{b}} P<0.0150$ and ${ }^{\mathrm{c}} P<0.0025$. 
Table 8. Estimated QTL variances (Var QTL) and non-QTL variance (Var non-QTL) from the pleiotropic model analysis for pairwise trait combinations \pm errors of estimates.

\begin{tabular}{|c|c|c|c|c|}
\hline \multirow{2}{*}{$\begin{array}{l}\text { Traits } 1 \text { and } 2 \\
\text { in combination }\end{array}$} & \multicolumn{2}{|c|}{ Trait 1} & \multicolumn{2}{|c|}{ Trait 2} \\
\hline & Var QTL & Var non-QTL & Var QTL & Var non-QTL \\
\hline Milk yield and & 6829.4 & $85,912.6$ & 74.23 & 215.06 \\
\hline fat yield & \pm 392.3 & \pm 4937.4 & \pm 4.26 & \pm 12.43 \\
\hline Milk yield and & $98,736.8$ & $13,941.89$ & 32.43 & 116.7 \\
\hline protein yield & \pm 5672.4 & \pm 8107.5 & \pm 1.86 & \pm 6.76 \\
\hline Fat yield and & 67.36 & 219.49 & 35.08 & 107.47 \\
\hline protein yield & \pm 3.87 & \pm 12.76 & \pm 2.01 & \pm 6.59 \\
\hline
\end{tabular}

the Akaike Information Criterion (AIC $=-2 \ln \mathrm{MLH}+$ 2 number of parameters). But no significance test was performed, due to the nonnested nature of the two models. The results from the close linkage model were not shown in detail. The standard errors of the estimates, obtained in all related analyses under this model, were high. Lebreton et al. (1998) presented a nonparametric bootstrap method for testing close linkage vs. pleiotropy. Our significant QTL findings for fat yield and protein yield in family $\mathrm{S} 2$ and in the univariate across family analyses were at most $4 \mathrm{cM}$ apart from each other. We did not conduct the empirical test of the pleiotropic model against the close linkage model, because we expected very limited power, given the small distance between these positions. Future finemapping analyses may provide more conclusive results. We will focus first on using additional informative markers for sire S2 being QTL heterozygous within an extended family structure. In a pre-finemapping analysis, such markers should be identified in the region between markers BM1329 (46 cM) and TGLA37 (66 cM) in order to avoid a bias, caused by an information gap in family S2.

Confidence intervals obtained by the bootstrapping method were quite large. If more than one single QTL was segregating on the chromosome, results obtained by this method might probably be incorrect. In addition, we estimated the confidence interval CI (95\%) across the families according to a method, suggested for saturated marker maps (Darvasi and Soller, 1997), based on $C I 95 M=3000 /\left(N \delta^{2}\right)$, when adapting this method to our design. Here, $\mathrm{N}$ is the number of genotyped animals, and $\delta$ is the substitution effect in units of residual standard deviation. For deriving the substitution effect from the QTL variance $(\delta Q T L=\sqrt{4 \operatorname{VarQTL}}$, $)$, we assumed a biallelic QTL with equal allele frequencies. When treating the whole non-QTL variance as "residual variance", then the computed confidence intervals CI (95\%) ranged from 8 to $13 \mathrm{cM}$ for fat and protein. Here, we did not expect a comparable small CI (95\%) of about $4 \mathrm{cM}$ as reported by Ron et al. (2001) from a singlefamily analysis.
The QTL variance component, which is part of the polygenic component in the fully reduced QTL model (MPOLY), was not biased by partitioning of the total variance into polygenic and residual variance. Estimates from a simple marker analysis (data not shown) confirmed a highly significant impact $(P<0.0036)$ of marker TGLA37 (at $66 \mathrm{cM}$ ) on fat yield, an effect of marker FBN13 (at $71 \mathrm{cM}$ ) on protein yield and milk yield, and supported the statement of conclusive results obtained by our study.

No previous results on multivariate QTL estimation in dairy cattle have been published to our knowledge. Canonical transformation (e.g., adapted by van Tassel et al., 2000) uncorrelates the traits and does not ensure that a QTL influences a single canonical trait separately (Knott and Haley, 2000). In breeding programs, we focus on several correlated traits. It is important to identify QTL influencing two or more traits of interest and traits of secondary importance and to distinguish pleiotropic from closely linked QTL.

Such knowledge is particularly of interest for use of QTL in marker-assisted selection. Furthermore, such findings may contribute to our understanding of the background of genetic correlations and to our ability to manipulate these correlations for breeding purposes.

Our results suggest the presence of one QTL at 68 cM on BTA6, affecting both fat and protein yield. This finding of a pleiotropic QTL influencing two positively correlated traits was in agreement with the estimated putative QTL positions using different genetic models, statistical methods, and algorithms. We cannot exclude some bias in the estimated QTL position, because we did not fit multiple QTL in the multivariate analysis, except for model MQ1Q2, allowing for two QTL, each affecting one trait. However, given our results, e.g., from the single-family analyses (Table 5) and from twoQTL analyses of single traits (here briefly discussed for fat yield), an important bias on the pleiotropic QTL finding for fat and protein yield does not seem to be likely.

Despite our increasing knowledge about the inheritance of important quantitative traits, this type of investigation needs to be continued. The physiological 
evidence is still at the very beginning, in particular with regard to pleiotropic effects and quantitative traits (Harlizius and Lende, 2001). An integrated effort of several disciplines such as quantitative genetics and functional genomics will "establish linkages between predisposition and physiology, enhancing our understanding of how economically important traits in animal agriculture are controlled and regulated..." (Pomp et al., 2001).

\section{CONCLUSION}

In this QTL investigation of chromosome BTA6, the prior suggestion of a pleiotropic QTL for fat and protein yield was confirmed. The QTL position at $68 \mathrm{cM}$ is bracketed by markers TGLA37 and FBN13. The pleiotropic QTL accounted for roughly $20 \%$ to $25 \%$ of the variation in both traits. This finding of a pleiotropic QTL from the (co)variance component analysis was in close agreement with QTL findings from the singletrait, single-family analysis. An additional suggestive pleiotropic QTL for milk and protein yield at $58 \mathrm{cM}$ failed to reach significance in two out of three hypothesis tests. Before utilizing the significant pleiotropic QTL for fat and protein yield in a breeding program, we propose to conduct a fine mapping study to more precisely characterize this QTL.

\section{ACKNOWLEDGEMENTS}

Support of the OECD and Research Grant WE 1786/ 2-2 by the Deutsche Forschungsgemeinschaft is thankfully acknowledged. I. Hoeschele acknowledges financial support from the US National Science Foundation (DBI-9723022) and from the US Department of Agriculture (NRICGP 99-35205-8568). Thanks to the VIT Verden for data providing, to J. Jensen, Danish Agricultural Institute Foulum, for supporting the computation work, and to V. Guiard for fruitful discussion.

\section{References}

Ashwell, M. S., and C. P. van Tassel. 1999. Detection of putative loci affecting milk, health and type traits in a US Holstein population using 70 microsatellite markers in a genome scan. J. Dairy Sci. 82:2497-2502.

Churchill, G., and R. Doerge. 1994. Empirical threshold values for quantitative trait mapping. Genetics 138:963-971.

Darvasi, A., and M. Soller. 1997. A simple method to calculate resolving power and confidence interval of QTL map location. Behav. Genet. 27:125-132.

Du, F., and I. Hoeschele. 1999. Computer Program performing Least Squares Analysis for QTL Detection. Available from inah@vt.edu.

Fernando, R. L., and M. Grossman. 1989. Marker-assisted selection using best linear unbiased prediction. Genet. Sel. Evol. 21:467-477.

Freyer, G., C. Kühn, R. Weikard, Q. Zhang, M. Mayer, and I. Hoeschele. 2002. Multiple QTL on Chromosome six in Dairy Cat- tle affecting Yield and Content Traits. J. Anim. Breed. Genet. 119:69-82.

George, A. W., P. M. Visscher, and C. S. Haley. 2000. Mapping quantitative Trait Loci in complex Pedigrees: A Two-Step Variance Component Approach. Genetics 156:2081-2091.

Georges, M., D. Nielsen, M. Mackinnon, A. Mishra, R. Okimoto, A. T. Pasquino, L. S. Sargeant, A. Sorensen, M. R. Steele, X. Zhao, J. E. Womack, and I. Hoeschele. 1995. Mapping quantitative trait loci controlling milk production in dairy cattle by exploiting progeny testing. Genetics 139:907-20.

Gomez-Raya, L., H. Klungeland, D. L. Vage, V. Olsaker, E. Fimland, G. Klementsdal, K. Ronningen, and S. Lien. 1998. Mapping QTL for milk production traits in Norwegian cattle. Proc. 6th World Congr. Genet. Appl. Livest. Prod. 26:429-432.

Grignola, F. E., I. Hoeschele, B. Tier. 1996. Mapping quantitative trait loci via residual maximum likelihood: I Methodology. Genet. Sel. Evol. 28:479-490.

Hansen, M., M. S. Lund, M. K. Sørensen, and L. G. Christensen. 2002. Genetic Parameters of Dairy Character, Protein Yield, Clinical Mastitis, and Other Diseases in the Danish Holstein Cattle. J. Dairy Sci. 85:445-452.

Harlizius, B., and T. van der Lende. 2001. Contribution of genomics to unravel the physiological background of economically important traits in livestock. Page 31 in Proc. 51st EAAP meeting, invited $\mathrm{GPh} 3$. Elsevier, the Hague.

Hoeschele, I., P. Uimari, F. E. Grignola, Q. Zhang, and K. M. Gage. 1997. Advances in statistical methods to map quantitative trait loci in outbred populations. Genetics 147:1445-1457.

Hoeschele, I. 2001. Mapping quantitative trait loci in outbred pedigrees. Pages 599-644 in Handbook of Statistical Genetics. D. J. Balding. Wiley \& Sons, New York.

Israel, C., and J. I. Weller. 2002. Estimation of quantitative trait loci effects in dairy cattle populations. J. Dairy Sci. 85:1285-1297.

Jensen, J., and P. Madsen. 1994. DMU: A package for the analysis of multivariate mixed models. Proc. 5th World Congr. Genet. Appl. Livest. Prod. 22:45-46. Univ. of Guelph, Guelph, Canada.

Jensen, J., E. Mantysaari, P. Madsen, and R. Thompson. 1997. Residual maximum likelihood estimation of (co)variance components in multivariate mixed linear models using average information. Indian Soc. Agric. Stat. 49:215-236.

Jiang, C., and Z. B. Zeng. 1995. Multiple trait analysis of genetic mapping for quantitative trait loci. Genetics 140:1111-1127.

Knott, S., J. M. Elsen, and C. Haley. 1994. Multiple marker mapping of quantitative trait loci in half sib populations. Proc. 5th World Congr. Genet. Appl. Livest. Prod. 21:33-36.

Knott, S. J., C. Haley. 2000. Multitrait least squares for QTL detection. Genetics 156:899-911.

Kühn, C., G. Freyer, R. Weikard, T. Goldammer, and M. Schwerin. 1999. Detection of QTL for milk production traits in cattle by application of a specifically developed marker map of BTA6. Anim. Genet. 30:1-8.

Lebreton C. M., P. M. Visscher, C. S. Haley, and A. Semikhodskii, S. A. Quarrie. 1999. A nonparametric bootstrap method for testing close linkage vs. pleiotropy of coincident quantitative trait loci. Genetics 150:931-43.

Lien, S., L. Gomez-Raya, T. Steine, E. Fimland, and S. Rogne. 1995. Associations between Casein Haplotypes and milk yield traits. J. Dairy Sci. 78:2047-2057.

Mosig, M. O., E. Lipkin, G. Khutoreskaya, E. Tchourzyna, M. Soller, and A. Friedmann. 2001. A whole Genome Scan for Quantitative Trait Loci Affecting Milk Protein Percentage in Israeli- Holstein Cattle, by Means of Selective Milk DNA Pooling in a Daughter Design, using an adjusted False Discovery Rate Criterion. Genetics 157:1683-1698.

Patterson, H. D., and R. Thompson. 1971. Recovery of inter-block information when block sizes are unequal. Biometrika 58:545554.

Pomp, D., A. R. Caetano, G. R. Bertani, C. D. Gladney, and R. K. Johnson. 2001. Applying Functional Genomics Research to the 
Study of Pig Reproduction. Reproduction, Suppl. 58 Available: http://www.srf-reproduction.org/journal/supplements/list.asp.

Ron, M., D. Klinger, E. Feldmesser, E. Seroussi, E. Ezra, and J. I. Weller. 2001. Multiple Quantitative Trait Locus Analysis of Bovine Chromosome 6 in the Israeli Holstein Population by a Daughter Design. Genetics 159:727-735.

Sørensen, P. 2000. Multivariate Methods to detect and estimate effects of single genes. Ph.D. Diss. (Lc 1697) Department of Animal Breeding and Genetics, Danish Institute of Agricultural Sciences Research Centre Foulum Denmark.

VanRaden, P. M., and G. R. Wiggans. 1991. Derivation, Calculation and Use of National Animal Model Information. J. Dairy Sci. 74: $2737-2746$.

van Tassel, C. P., M. S. Ashwell, and T. S. Sonstegard. 2000. Detection of Putative Loci Affecting Milk, Health, and Conformation Traits in a US Holstein Population Using 105 Microsatellite Markers. J. Dairy Sci. 83:1865-1872.

Velmala, R. J., H. J. Vilkki, K. T. Elo, D. J. de Koning, and A. V. Mäki-Tanila. 1999. A search for quantitative trait loci for milk production traits on chromosome 6 in Finnish Ayrshire cattle. Anim. Genet. 30:136-143.

VIT Jahresbericht. 2001. Available: http://vit.de.

Whittaker, J. C., R. Thompson, and P. M. Visscher. 1996. On the mapping of QTL by regression of phenotype on marker-type. Heredity 77:23-32.

Zhang, Q., D. Boichard, I. Hoeschele, C. Ernst, A. Eggen, B. Murkve, M. Pfister-Genskow, L. A. Witte, F. E. Grignola, P. Uimari, G. Thaller, and M. D. Bishop. 1998. Mapping quantitative trait loci for milk production and health of dairy cattle in a large outbred pedigree. Genetics 149:1959-1973. 